\title{
Green Synthesis and Characterization of Gold Nanoparticles Using Onion (Allium cepa) Extract
}

\author{
Umesh Kumar Parida ${ }^{1}$, Birendra Kumar Bindhani ${ }^{2}$, Padmalochan Nayak ${ }^{*}$ \\ ${ }^{1}$ P. L. Nayak Research Foundation, Manorama Bhavan, Cuttack, India \\ ${ }^{2}$ KIIT School of Biotechnology, KIIT University, Patia Bhubaneswar, India \\ E-mail:"plnayak@rediffmail.com \\ Received September 28, 2011; revised November 3, 2011; accepted November 12, 2011
}

\begin{abstract}
In the present research program, cost effective and environment friendly gold nanoparticless were synthesized using the onion (Allium cepa) extract as the reducing agent. The nanoparticless were characterized using UV-visble, XRD, and SEM, TEM methods. The absorption peak at $540 \mathrm{~nm}$ was found to be broaden with increase in time indicating the polydispersity nature of the nanoparticles. The XRD results suggested that the crystallization of the bio-organic phase occurs on the surface of the gold nanoparticles or vice versa. The broadening of peaks in the XRD patterns was attributed to particle size effects. The internalization of nanoparticles within cells could occur via processes including phagocytosis, fluid-phase endocytosis and receptor mediated endocytosis.
\end{abstract}

Keywords: Biosynthesis, Gold Nanoparticles, Allium cepa, Green-Gold

\section{Introduction}

The field of nanotechnology is one of the most active areas of research in modern material sciences. Nanotechnology is a field that is developing day by day, making an impact in all spheres of human life and creating a growing sense of excitement in the life sciences especially biomedical devices and biotechnology. Recently, the green chemistry which aims to reduce or eliminate substances hazardous to human health and the environment in the design, development and implementation of chemical processes and products is becoming more and more important [1,2]. To comply with the 12 principles of green chemistry, many researches tried to avoid or reduce the uses of hazardous chemicals and solvents, such as using natural materials instead of traditional toxic chemicals [3-5].The use of nanoparticles is gaining importance in the present century as they possess definite chemical, optical and mechanical properties. Metal nanoparticles are of importance due to their potential applications in catalysis, photonics, biomedicine, antimicrobial activity and optics [6,7] Nanotechnology is expected to open new avenues to fight and prevent disease using atomic scale tailoring of materials. This is indeed a challenging field of research with unlimited future prospects.

The use of phytochemicals in the synthesis of nanopar- ticles is an important symbiosis between nanotechnology and green chemistry [8-10]. As the nano revolution unfolds, it is imperative to develop "nano-naturo" connections between nanotechnology and green domains of the nature. Production of nanoparticles under nontoxic green conditions is of vital importance to address growing concerns on the overall toxicity of nanoparticles for medical and technological applications [11-13]. The power of phytochemicals, which initiate varieties of chemical transformations within biological systems, is well known [12, 14-16]. For example, a high level of genistein found in soybeans is both a phytoestrogen and antioxidant, and has been extensively used to treat conditions affected by estrogen levels in the body [17,18]. Polyphenolic flavonoid in tea, of which epigallocatechin gallate (EGCG) is the major constituent, has anticarcinogenic activity [19, 20]. Cinnamon a common household spice is known to have potential properties to treat diabetes mellitus [21, 22]. While the tremendous health benefits of chemical cocktails present within tea, soya, cinnamon is beyond doubt, the actual applications of the chemical reduction power of the myriad of chemicals present in herbs and spices is still in infancy.

Many biotechnological applications such as remediation of toxic metals employ microorganisms such as bacteria [23] and yeast [24] for the synthesis of nanopar- 
$A L$.

ticles. Nair and Pradeep [25] have synthesized nanoparticles of gold, silver and their alloys by the reaction of the corresponding metal ions within cells of lactic acid bacteria present in buttermilk. The bacteria [26] and algae [27] have been used for the synthesis of gold nanoparticle.

Gold nanoparticless can be successfully synthesized by traditionally chemical and physical methods. However, these methods strongly depend on severe reaction conditions, for example, aggressive agents like sodium borohydride, hydrazinium hydroxide, cetyltriethylammnonium bromide, and harmful solvent system to environment and ecology, higher temperature and higher pressure have been used. To pursue a healthy life and space, it is imperative to develop a clean synthetic approach using the concept of "green chemistry" to obtain nanomaterials targeted for different applications, especially in biomedical fields.

In recent years, plant-mediated biological synthesis of nanoparticles is gaining importance due to its simplicity and eco-friendliness. Recently the biosynthesis of gold nanoparticles by plants such as Terminalia catappa [28], tea [29], lemongrass [30] has been reported. On a more fundamental level, it would be interesting to study the nature of nanoparticles formed using extracts from different parts of the plant [31-35]. A survey of the literature reveals that onion extract has not been used for the synthesis of gold nanoparticles.

In the present research program, we wish to report the green synthesis of gold nanoparticles using the extract of onion (Allium cepa). The gold nanoparticles were characterized by using UV-visible spectra, SEM, XRD and TEM.

\section{Experimental}

\subsection{Reagents and Chemicals}

Tetrachloroauric acid $\left(\mathrm{HAuCl}_{4} \cdot \mathrm{XH}_{2} \mathrm{O}\right)$ was obtained from Sigma Chemicals. Freshly prepared triple distilled water was used throughout the experimental work.

\subsection{Biological Synthesis of Gold Nanoparticles}

The broth used for the reduction of $\mathrm{Au}^{3+}$ ions to $\mathrm{Au}^{0}$ was prepared by taking $10 \mathrm{~g}$ of thoroughly washed and finely cut onion (Allium cepa) in a $500 \mathrm{ml}$ Erlenmeyer flask with $40 \mathrm{~mL}$ of sterile distilled water and was boiled for $15 \mathrm{~min}$. In a typical experiment, $0.2 \mathrm{ml}$ of broth was added to $50 \mathrm{ml}$ of $10^{-3} \mathrm{M}$ aqueous chloroauric acid $\left(\mathrm{HAuCl}_{4}\right)$ solution. Within an hour cherry yellowish red color solution was obtained (Figure 1). The gold nano particles so prepared were stabilized by adding $2 \%$ of

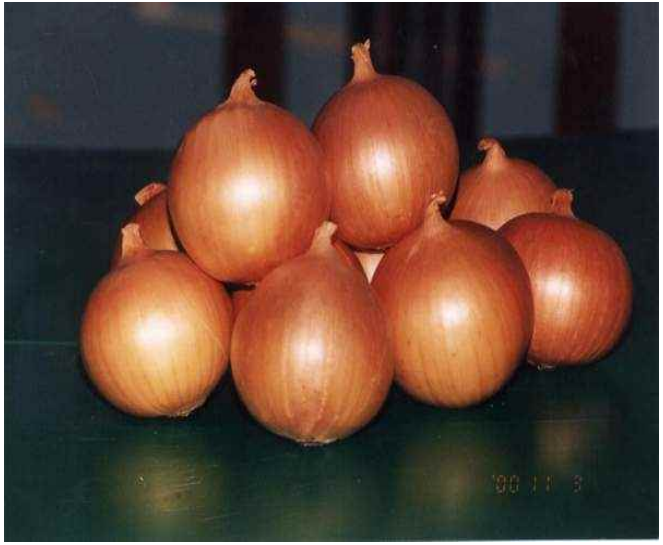

(a)
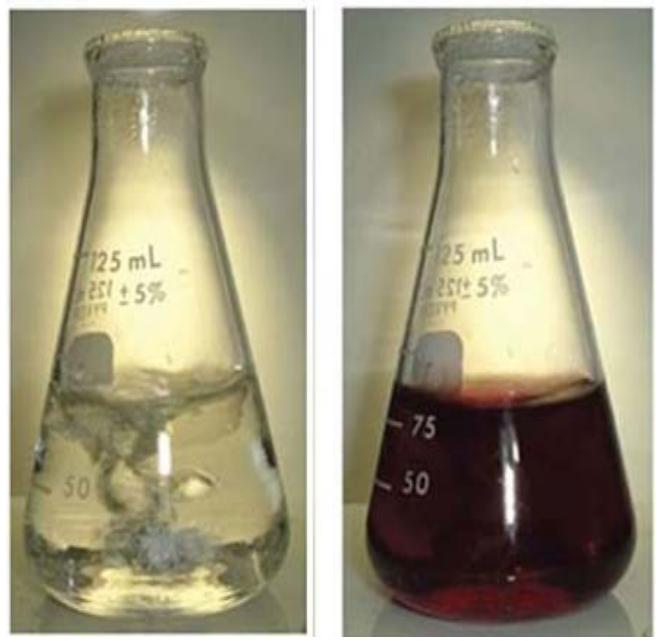

(b)

Figure 1. (a) Allium cepa; (b) Picture of aqueous solution of $10^{-3} \mathrm{mM} \mathrm{AuCl}_{3}$ with Allium cepa.

aqueous chitosan solution.Onion juice contains vitamin $\mathrm{C}$ which reduces the $\mathrm{Au}^{3+}$ to $\mathrm{Au}^{0}$ [36].

\section{Cell Culture}

MCF-7 breast cancer cells and were obtained from SCB Medical Cuttack, India and MCF-7 cells were maintained in MEM with nonessential amino acids, $10 \mathrm{pg} \cdot \mathrm{ml}^{-1}$ phenol red, 10 mM HEPES, 6 ngml-1 insulin, 100 units $\mathrm{ml}^{-1}$ penicillin, $100 \mathrm{pg} \cdot \mathrm{ml}^{-1}$ streptomycin, and $5 \%$ charcoal-stripped calf serum (maintenance medium).

\section{Cell Internalization Procedure}

About 16,000 cells (MCF-7) were plated into each well in a 6 well plate and were incubated at $37^{\circ} \mathrm{C}$ for $20.0 \mathrm{hr}$ to allow the cells to recover. The medium from each well was aspirated and $4 \mathrm{ml}$ of fresh growth medium was added per each well. Cells were allowed to grow until 
they reached confluence by changing the medium every alternate day. To the confluent cell layer, $150 \mu \mathrm{l}$ of AuNps solution was added and further incubated for 4 hrs at $37^{\circ} \mathrm{C}$. The medium was then aspirated from each well and the cell layer was rinsed 3 times with complete growth medium to remove any traces of uninternalized AuNps. The cell layer was washed with CMFH-EDTA (Calcium-Magnesium-Free-Hank's + HEPES-EDTA) solution to remove all traces of serum, a trypsin inhibitor. About $0.5 \mathrm{ml}$ of $0.1 \mathrm{M}$ Trypsin-EDTA solution was added to each well to detach the cell layer. Detached cells were dispersed in $4 \mathrm{ml}$ of complete growth medium and gently pipetted out of the well. The cell suspension was transferred into a centrifuge tube and centrifuged at approximately $125 \times \mathrm{g}$ for 5 minutes. Supernatant solution was discarded and cell pellet was fixed with $0.1 \mathrm{M}$ Na-Cacodylate buffer containing $2 \%$ glutaraldehyde and $2 \%$ paraformaldehyde. The pellets were post-fixed with $1 \%$ osmium tetraoxide, dehydrated and embedded in Epon/ Spurr's resin and $80 \mathrm{~nm}$ sections were collected.

\subsection{UV-Vis Spectroscopy Studies}

UV-vis spectroscopy measurements of the gold nanotriangles were carried out on a UV-vis Spectrophotometer (UV-245 Shimadzu).

\subsection{X-Ray Diffraction (XRD) Measurement}

XRD measurements of the were done on a Phillips PW 1830 instrument operating at a voltage of $40 \mathrm{KV}$ and current of $20 \mathrm{~mA}$ with $\mathrm{Cu} \mathrm{K}$ radiation.

\subsection{SEM Analysis of Gold Nanoparticles}

Scanning Electron Microscopic (SEM) analysis was done using Hitachi S-4500 SEM machine. Thin films of the sample were prepared on a carbon coated copper grid by just dropping a very small amount of the sample on the grid, extra solution was removed using a blotting paper and then the film on the SEM grid were allowed to dry by putting it under a mercury lamp for $5 \mathrm{~min}$.

\subsection{TEM Measurements}

TEM measurements were performed on a JEOL model $1200 \mathrm{EX}$ instrument operated at an accelerating voltage at $80 \mathrm{kV}$.

\section{Results and Discussion}

Onion contains vitamin $\mathrm{C}$ as one of its constituents. Vitamin $\mathrm{C}$ is responsible for the reduction of $\mathrm{Au}^{3+}$ to $\mathrm{Au}^{0}$.

\subsection{UV-Vis Spectra Analysis}

The reduction of aqueous $\mathrm{HAuCl}_{4}$ ions during reaction with the Allium cepa extract was followed by UV-vis spectroscopy. Figure 2 show the UV-vis absorption spectra recorded from the Allium cepa extract, prepared from aqueous gold nanoparticle solution. A strong resonance at $540 \mathrm{~nm}$ is clearly seen and arises due to the excitation of surface plasmon vibrations in the gold nanoparticles.

\subsection{X-Ray Diffraction Studies}

Structural characterization has been performed using XRD analysis and the typical XRD pattern for gold nanoparticles is shown in Figure 3. In addition to these three peaks there are some unidentified peaks appeared in the XRD pattern. The characteristic peaks corresponding to (111), (200), (220) of Au are located at $2 \theta=38.29^{\circ}$, $44.43^{\circ}$ and $64.68^{\circ}$, respectively. The result indicates that the sample is composed of crystalline gold.

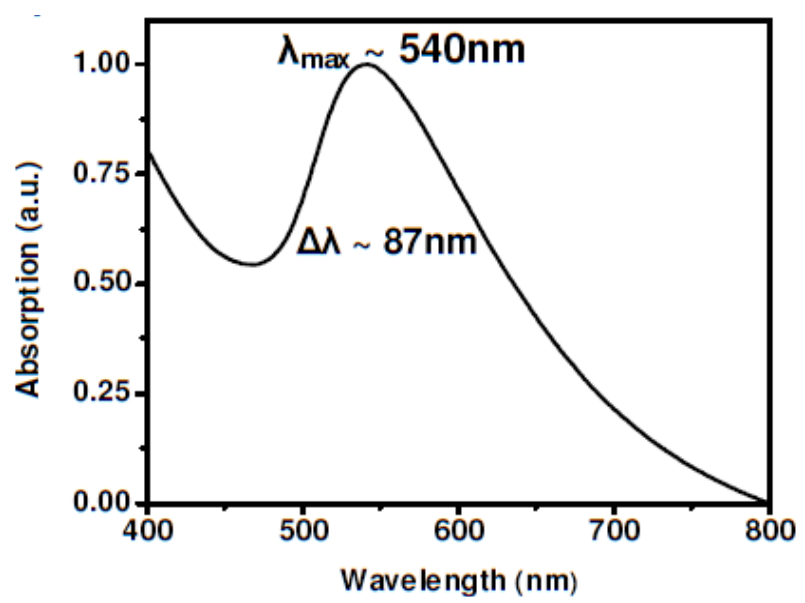

Figure 2. UV-vis absorption spectra of gold nanoparticles.

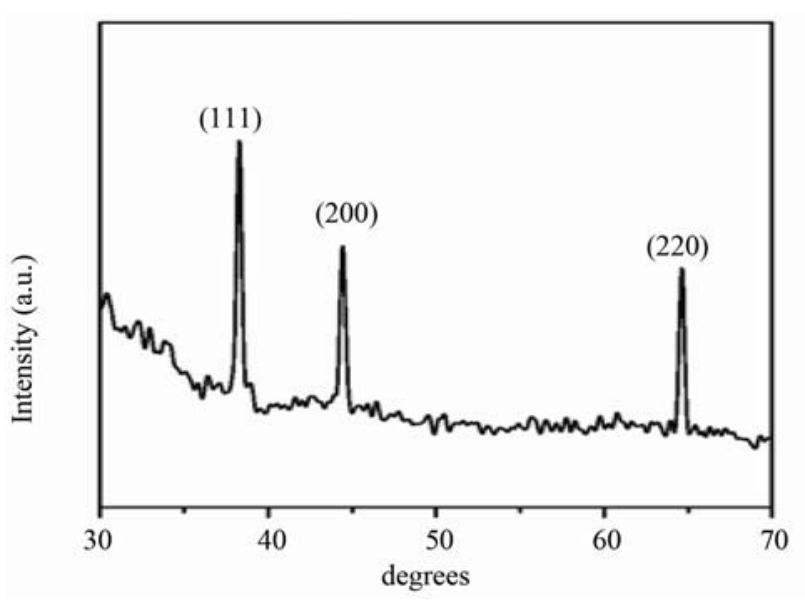

Figure 3. XRD of gold nanoparticle. 


\subsection{Scanning Electron Microscopy of Gold Nano Particles}

The SEM photograph of gold nanoparticles are shown in Figure 4. SEM photograph of gold nanoparticles clearly indicates that in the room temperature synthesized samples the size the average size of the nanoparticles is $\sim 100$ nm, with spherical and cubic shape.

\section{Cellular Internalization Studies}

TEM images of breast tumor (MCF-7) cells treated with AuNPs unequivocally validated our hypothesis. Significant internalization of nanoparticles via endocytosis within the MCF-7 was observed (Figures 5). The internalization of nanoparticles within cells could occur via processes including phagocytosis, fluid-phase endocytosis, and receptor mediated endocytosis. The viability of

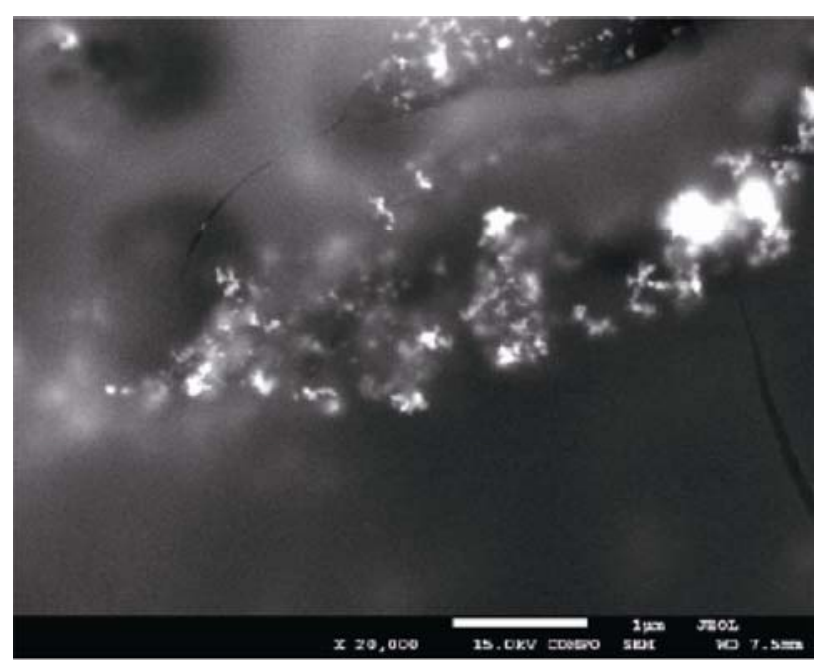

Figure 4. SEM image of gold nanoparticles.

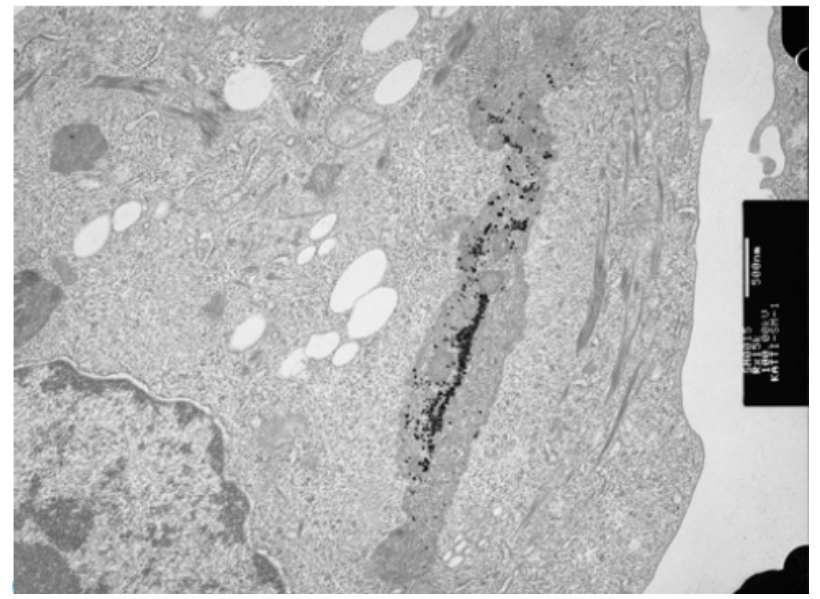

Figure 5. TEM Images of different MCF-7 cells showing uptake of Allium cepa-AuNps. and MCF-7 cells post-internalization suggests that the phytochemical coating renders the nanoparticles nontoxic to cells. Such a harmless internalization of AuNps will provide new opportunities for probing cellular processes via nanoparticulate-mediated imaging.

\section{Conclusions}

The rapid green synthesis of gold nanoparticles using Allium cepa extract has been demonstrated. The nanoparticles were stabilized using aqueous chitosan solution. The reduction of gold nanoparticles takes place because of the presence of vitamin $\mathrm{C}$ in onion extract. The UVvisible spectra measurements were carried out at $540 \mathrm{~nm}$ with sharp peak. The surface of the nanoparticle was ascertained from the SEM and crystallinity was observed from the XRD spectra. The viability of and MCF-7 cells post-internalization suggests that the phytochemical coating renders the nanoparticles non-toxic to cells.

\section{References}

[1] M. Poliakoff and P. Anastas, "A Principled Stance," Nature, Vol. 413, 2001, p. 257. doi:10.1038/35095133

[2] M. Poliakoff, J. M. Fitzpatrick, T. R. Farren and P. T. Anastas, "Green Chemistry: Science and Politics of Change," Science, Vol. 297, No. 5582, 2002, pp. 807-810. doi:10.1126/science.297.5582.807

[3] R. A. Gross and B. Kalra, "Biodegradable Polymers for the Environment," Science, Vol. 297, No. 5582, 2002, pp. 803-807. doi:10.1126/science.297.5582.803

[4] J. M. DeSimone, "Practical Approaches to Green Solvents," Science, Vol. 297, No. 5582, 2002, pp. 799-803. doi:10.1126/science.1069622

[5] P. Raveendran, J. Fu and S. L. Wallen, "Completely 'Green' Synthesis and Stabilization of Metal Nanoparticles," Journal of American Chemical Society, Vol. 125, No. 46, 2003 , pp. 13940-13941. doi:10.1021/ja029267j

[6] K. Govindraju, V. Kiruthiga and G. Singaravelu, "Evaluation of Biosynthesized Silver Nanoparticles against Fungal Pathogens of Mulberry Morus Indica," Journal of Biopesticides, Vol. 1, 2008, pp. 101-104.

[7] K. Govindraju, V. Kiruthiga, K. V. Ganesh and G. Singaravelu, "Extracellular Synthesis of Silver Nanoparticles by a Marine Alga, Sargassum wightii Grevilli and Their Antibacterial Effects," Journal of Nanoscience and Nanotechnology, Vol. 9, No. 9, 2009, pp. 5497-5501. doi:10.1166/jnn.2009.1199

[8] J. Huang, Q. Li, D. Sun, Y. Lu, Y. Su, X. Yang, H. Wang, Y. Wang, W. Shao, N. J. Hong and C. Chen, "Biosynthesis of Silver and Gold Nanoparticles by Novel Sundried Cinnamomum camphora Leaf," Nanotechnology, Vol. 18, No. 10, 2007, pp. 105104-105115. doi:10.1088/0957-4484/18/10/105104

[9] L. Jorge, G. Torresdey, E. Gomez, J. R. Peralta-Videa, J. 
G. Parsons, H. Troiani and M. J. Yacaman, "Phytoremediation of Heavy Metals and Study of the Metal Coordi- nation by X-Ray Absorption Spectroscopy," Langmuir, Vol. 19, 2003, p. 1357.

[10] J. L. Gardea-Torresdey, K. J. Tiemann, J. G. Parsons, G. Gamez, I. Herrera and M. Jose Yacaman, "Investigation into the Mechanism(s) of $\mathrm{Au}$ (III) Binding and Reduction by Alfalfa Biomass," Microchemical Journal, Vol. 71, No. 2-3, 2002, pp. 193-204. doi:10.1016/S0026-265X(02)00011-5

[11] R. Hardman, “A Toxicologic Review of Quantum Dots: Toxicity Depends on Physicochemical and Environmental Factors," Environmantal Health Perspectives, Vol. 114, No. 2, 2006, pp. 165-172. doi:10.1289/ehp.8284

[12] J. Curtis, M. Greenberg, J. Kester, S. Phillips and G. Krieger, "Nanotechnology and Nanotoxicology: A Primer for Clinicians," Toxicological Reviews, Vol. 25, No. 4, 2006, pp. 245-260. doi:10.2165/00139709-200625040-00005

[13] N. Lewinski, V. Colvin and R. Drezek, "Cytotoxicity of Nanoparticles," Small, Vol. 4, No. 1, 2008, pp. 26-49. doi:10.1002/smll.200700595

[14] J. C. Espín, M. T. García-Conesa and F. A. Tomás-Barberán, "Nutraceuticals: Facts and Fiction," Phytochemistry, Vol. 68, No. 22-24, 2007, pp. 2986-3008. doi:10.1016/j.phytochem.2007.09.014

[15] S. Rochfort and J. Panozzo, "Phytochemicals for Health, the Role of Pulses," Journal of Agricultural and Food Chemistry, Vol. 55, No. 20, 2007, pp. 7981-7994. doi:10.1021/if071704w

[16] K. D. R. Setchell, N. M. Brown, P. Desai, L. Zimmer-Nechemias, B. E. Wolfe, W. T. Brashear, A. S. Kirschner, A. Cassidy and J. E. Heubi, "Bioavailability of Pure Isoflavones In Healthy Humans and Analysis of Commercial Soy Isoflavone Supplements," Journal of Nutrition, Vol. 131, No. 4, 2001, pp. 1362S-1275S.

[17] P. J. Magee and I. R. Rowland, "Phyto-Oestrogens, Their Mechanism of Action: Current Evidence for a Role in Breast and Prostate Cancer," British Journal of Nutrition, Vol. 91, No. 4, 2004, pp. 513-520. doi:10.1079/BJN20031075

[18] J. L. Limer and V. Speirs, "Phyto-Oestrogens and Breast Cancer Chemoprevention," Breast Cancer Research, Vol. 6, 2004, pp. 119-127. doi:10.1186/bcr781

[19] O. J. Bandele and N. Osheroff, "(-)-Epigallocatechin Gallate, "A Major Constituent of Green Tea, Poisons Human Type II Topoisomerases" Chemical Research in Toxicology, Vol. 21, No. 4, 2008, pp. 936-943. doi:10.1021/tx700434v

[20] S. Shankar, S. Ganapathy and R. K. Srivastava, "Green Tea Polyphenols: Biology and Therapeutic Implications in Cancer," Front Biosci, Vol. 12, 2007, pp. 4881-4899. doi: $10.2741 / 2435$

[21] K. Dannemann, W. Hecker, H. Haberland, A. Herbst, A. Galler, T. Schäfer, E. Brähler, W. Kiess and T. M. Kapellen, "Use of Complementary and Alternative Medicine in Children with Type 1 Diabetes Mellitus-Prevalence, Patterns of Use, and Costs," Pediatr Diabetes, 2008.
[22] S. Suppapitiporn and N. Kanpaksi, "The Effect of Cinnamon Cassia Powder in Type 2 Diabetes Mellitus," Journal of the Medical Association of Thailand, Vol. 89 Supplement 3, 2006, p. 200.

[23] J. R. Stephen and S. J. Maenaughton, "Fungus-Mediated Synthesis of Silver Nanoparticles and Their Immobilization in the Mycelial Matrix: A Novel Biological Approach to Nanoparticle Synthesis," Current Opinon in Biotechnology, Vol. 10, No. 3, 1999, p. 230. doi:10.1016/S0958-1669(99)80040-8

[24] R. K. Mehra and D. R. Wingre, "Methabenzthiazuron on Oxygen Evolution and Cell Growth," Journal of Cellular Biochemistry, Vol. 45, No. 1, 1991, p. 30. doi:10.1002/jcb.240450109

[25] B. Nair and T. Pradeep, "Preparation of Gold Nanoparticles from Mirabilis Jalapa Flowers," Crystal Growth Design, Vol. 2, No. 4, 2002, pp. 293-298. doi: $10.1021 / \operatorname{cg} 0255164$

[26] G. Southam and T. J. Beveridge, "The Use of Microorganisms for the Formation of Metal Nanoparticles," Geochimica et Cosmochimica Acta, Vol. 60, No. 22, 1996, p. 4369. doi:10.1016/S0016-7037(96)00235-9

[27] M. G. Robinson, L. N. Brown and D. Beverley, "Effect of Gold (III) on the Fouling Diatom Amphora Coffeae- formis: Uptake, Toxicity and Interactions with Copper," Biofouling, Vol. 11, No. 1, 1997, pp. 59-79. doi:10.1080/08927019709378320

[28] B. Ankamwar, "Biosynthesis of Gold Nanoparticles (GreenGold) Using Leaf Extract of Terminalia Catappa," E-Journal of Chemistry, Vol. 7, No. 4, 2010, pp. 1334-1339.

[29] S. K. Nune, N. Chanda, R. Shukla, K. Katti, R. R. Kulkarni, S. Thilakavathy, S. Mekapothula, R. Kannan and K. V. Katti, "Green Nanotechnology from Tea: Phytochemicals in Tea as Building Blocks for Production of Biocompatible Gold Nanoparticles," Journal of Materials Chemistry, Vol. 10, 2009, p. 1039.

[30] S. S. Shiv, A. Rai, B. Ankamwar, A. Singh, A. Ahmad and M. Sastry, "Biological Synthesis of Triangular Gold Nanoprisms," Nature Materials, Vol. 3, 2004, pp. 482-488. doi:10.1038/nmat1152

[31] F. E. Kandil, A. M. Soliman, S. R. Skodack and T. J. Mabry, "In Vitro Antibacterial Activity of the Extracts Derived from Terminalia catappa," Asian Journal of Chemistry, Vol. 11, 1999, pp. 1001-1004.

[32] S. P. Pawar and S. C. Pal, "Antimicrobial Activity of Extracts of Terminalia catappa Root," Indian Journa of Medical Sciences, Vol. 56, No. 6, 2002, pp. 276-278.

[33] T. F. Ko, Y. M. Weng and R. Y. Chiou, "Antimutagenicity of Supercritical $\mathrm{CO}_{2}$ Extracts of Terminalia catappa Leaves and Cytotoxicity of the Extracts to Human Hepatoma Cells," Journal of Agricultural and Food Chemistry, Vol. 11, No. 9, 2002, pp. 5343-5348. doi:10.1021/if0203500

[34] C. C. Lin, Y. F. Hsu and T. C. Lin, "Evaluation of Antioxidant Activity of Eleven Thai Medicinal Herbs," Anticancer Research, Vol. 21 No. 1A, 2001, pp. 237-243.

[35] C. C. Chyou, S. Y. Tsai, P. T. Ko and J. L. Mau, "Ter- 
minalia catappa Linn. (Combretaceae)," Food Chemistry, Vol. 78. No. 4, 2002, pp. 483-488.

[36] J. Saffi, L. Sonego, Q. D. Varela and M. Salvador "Antioxidant Activity of L-Ascorbic Acid in Wild Type and
Superoxide Dismutase Deficient Strains of Saccharomyces Cerevisiae," Redox Report, Vo1. 11, 2006, pp. 179- 184. 